\title{
Validity and Reproducibility of a Semi-Quantitative Food Frequency Questionnaire Adapted to an Israeli Population
}

\author{
Dorit Itzhaki ${ }^{1}$, Hedy S. Rennert ${ }^{2}$, Geila S. Rozen ${ }^{3}$ and Gad Rennert*,2 \\ ${ }^{1}$ Sub-District Health Office, Akko S.D-Northern District, Ministry of Health, Akko, Israel \\ ${ }^{2}$ Department of Community Medicine and Epidemiology, CHS National Cancer Control Center, Carmel Medical Center \\ and Technion Faculty of Medicine, Haifa, Israel \\ ${ }^{3}$ Department of Clinical Nutrition, Rambam Medical Center, Haifa, Israel
}

\begin{abstract}
Assessment of individual representative dietary practices in epidemiologic research has long been a challenge. Given the differences in eating habits and availability of foods between populations, a study was set to test the reproducibility and validity of an Israeli-adapted semi-quantitative food frequency questionnaire (SFFQ) used in case-control studies of cancer etiology.

Two hundred volunteers between the ages 22-60 were randomly assigned to either complete an SFFQ independently or by nutritionist interview. Participants were then asked to fill out a 3-day food record (FR). SSFQ was repeated 3 months later. Reliability of the repeated SSFQ was examined using Pearson correlations; paired t-tests and Mann-Whitney Rank Test were used to measure reliability and validity of the SFFQ.

Overall, there was $>85 \%$ agreement \pm 1 category between the two encounters in over $75 \%$ of the food items. Percent of calories from proteins, fats and carbohydrates were similar for both self-administered and interviewed groups. The majority of correlations between the $1^{\text {st }}$ and $2^{\text {nd }}$ SSFQs for the micronutrients were above 0.75 . No differences were noted in percent energy from proteins, fats or carbohydrates between self-administered and interviewer-assisted SSFQ and FR.
\end{abstract}

The Israeli FFQ was found in our study to be highly reproducible and valid compared to a dietary record.

Keywords: Food frequency questionnaire, reliability, validity, Israel.

\section{INTRODUCTION}

Assessment of individual representative dietary practices in epidemiologic research has long been a challenge [1-3]. The semi-quantitative food frequency questionnaire (SFFQ), developed by Willet et al. for the Nurses Health Study [4], has been validated for use in various populations [5-7]. However it cannot be assumed that the same tool will be valid in an Israeli population, given the differences in eating habits and availability of foods. A strict translation of the questionnaire is insufficient - many foods commonly consumed in Israel are not included in the questionnaire and vice versa; therefore an effort was made to adapt and validate the SFFQ for use in Israel. The questionnaire was translated into Hebrew and adapted to reflect the foods available and consumed in Israel. As there is no true "gold standard" for nutritional assessment for epidemiological studies, validation is attempted by comparing one method against another that is thought to be more accurate in clinical service [7-10]. The questionnaire was further used by us in our case-control studies of colorectal cancer etiology (MECC) and breast cancer etiology (BCA) in Israel.

The purpose of this study was to test the reproducibility of the Israeli-adapted SFFQ and its validity when compared to a 3-day food record, both in terms of nutrient components and for specific food items.

*Address correspondence to this author at the CHS National Cancer Control Center, Carmel Medical Center, 7 Michal St, Haifa 34362, Israel;

E-mail: rennert@tx.technion.ac.il

\section{MATERIALS AND METHODOLOGY}

\section{Study Population}

The study population consisted of 200 volunteers between the ages 22-60 who were randomly assigned to one of two groups. One group completed the SSFQ independently after a 10-minute explanation by a trained nutritionist who was available for questions while they filled out the form. Upon completion the nutritionist reviewed the form with the participant to ensure completeness. In the second group the SFFQ was completed by interview by the same nutritionist. All participants were then asked to fill out a 3-day food record and were given instructions to record all food and beverage intake. SSFQ was repeated 3 months later, selfadministered or by interview, according to the original group allocation (Fig. 1).

Excluded were pregnant or breastfeeding women, new immigrants less than a year in the country, people unable to read and write in Hebrew and persons with serious illnesses before or diagnosed during the 3-month study period. Also excluded were persons who did not complete all three parts of the study. New volunteers were recruited to replace the dropouts until the goal of 200 subjects was reached.

\section{Dietary Methods}

Two methods of dietary evaluation were employed in this study: The semi-quantitative food frequency questionnaire (SFFQ) and a 3-day food record (FR). 


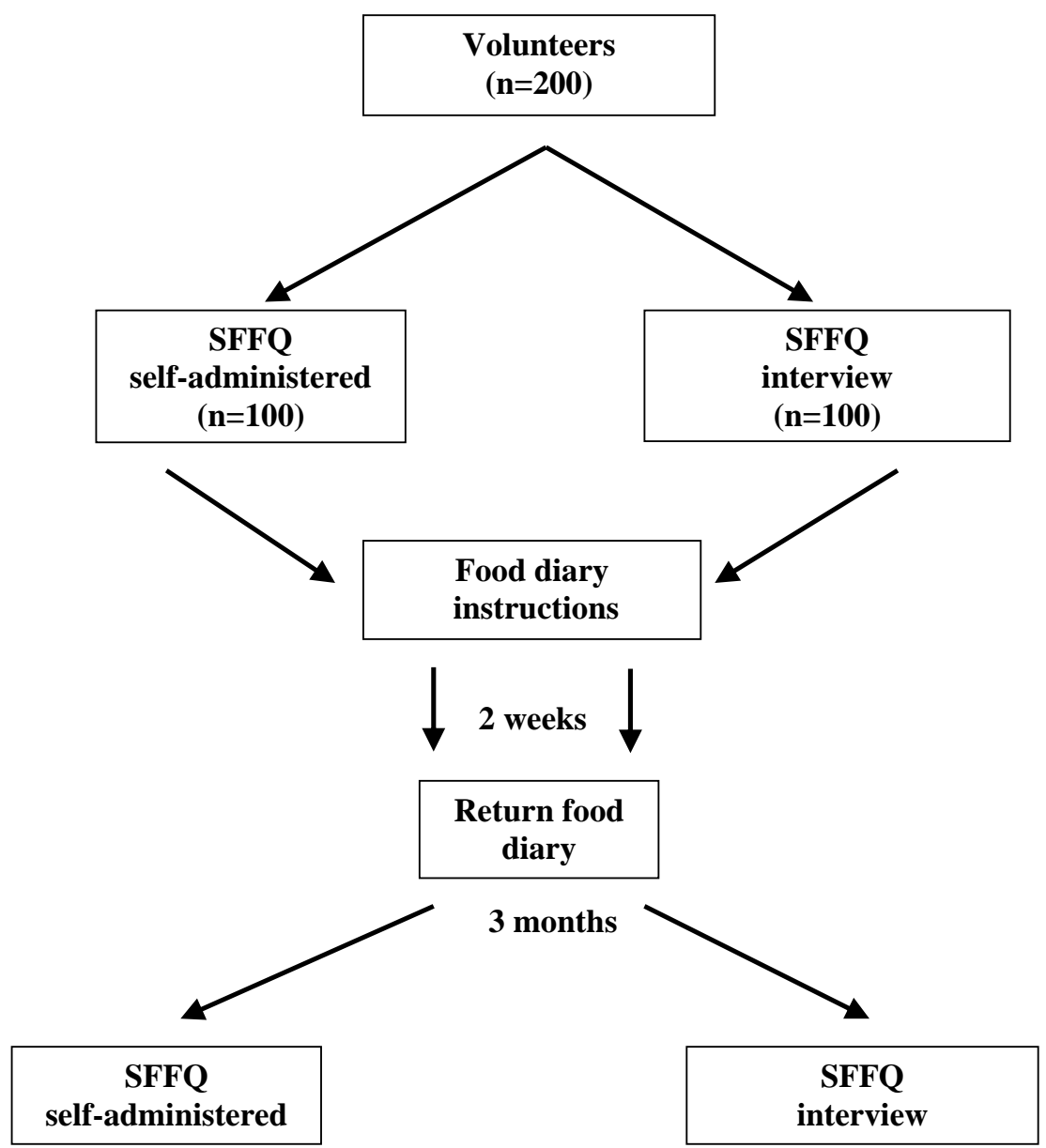

Fig. (1). The design scheme of the study.

Table 1. Correlation of Percent Calories from Protein, Fat and Carbohydrates Between SFFQ1 and SFFQ2, by Completion Method

\begin{tabular}{|c|c|c|c|}
\hline Nutritional Component & Interview $(n=100)$ Pearson $r^{1}$ & Self-administered $(n=100)$ Pearson $r^{1}$ & Total Sample $(n=200)$ Pearson $r^{1}$ \\
\hline Fat & 0.75 & 0.66 & 0.71 \\
\hline Carbohydrates & 0.80 & 0.68 & 0.74 \\
\hline
\end{tabular}

${ }^{1}$ Pearson correlations, all $\mathrm{p}<0.0001$

1) The SFFQ consisted of 168 food items with portion sizes designated for each item. Frequency of consumption for each item was recorded into one of 9 pre-coded categories: 0 or $<1$ time/month, 1-3 times/month, 1/week, 2-4/week, 56/week, 1/day, 2-3/day, 4-5/day, 6+/day.

2) All participants were asked to keep a 3-day food record (FR) and to record all food, drink and vitamin consumption immediately after eating and to include the hour, the quantity consumed and method of preparation.

\section{Data Analysis}

All dietary analyses (SSFQ and FR) were done using an Israeli nutritional database established at the Department of Clinical Nutrition at Rambam Medical Center. The database provided data on overall caloric intake, proteins, carbohydrates and fats in addition to 33 nutritional components. Results from this database, along with demographic data were analyzed using SPSS. Reliability of the repeated SFFQ's was examined using Pearson correlations and paired t-tests. Comparisons between the two methods of completion were done using t-tests and Mann-Whitney Rank Test. Validity of the SSFQ against the FR was done using t-tests and Pearson correlations. For all tests, the level of significance used was $\mathrm{p} \leq 0.05$.

\section{RESULTS}

\section{a. Reliability-Reproducibility}

Each item on the SFFQ was compared for consistency between the $1^{\text {st }}$ and $2^{\text {nd }}$ times of completion. Overall, there was $>85 \%$ agreement \pm 1 category in over $75 \%$ of the food 
Table 2. Correlation Between SFFQ1 and SFFQ2 for all Nutritional Components, by Completion Method

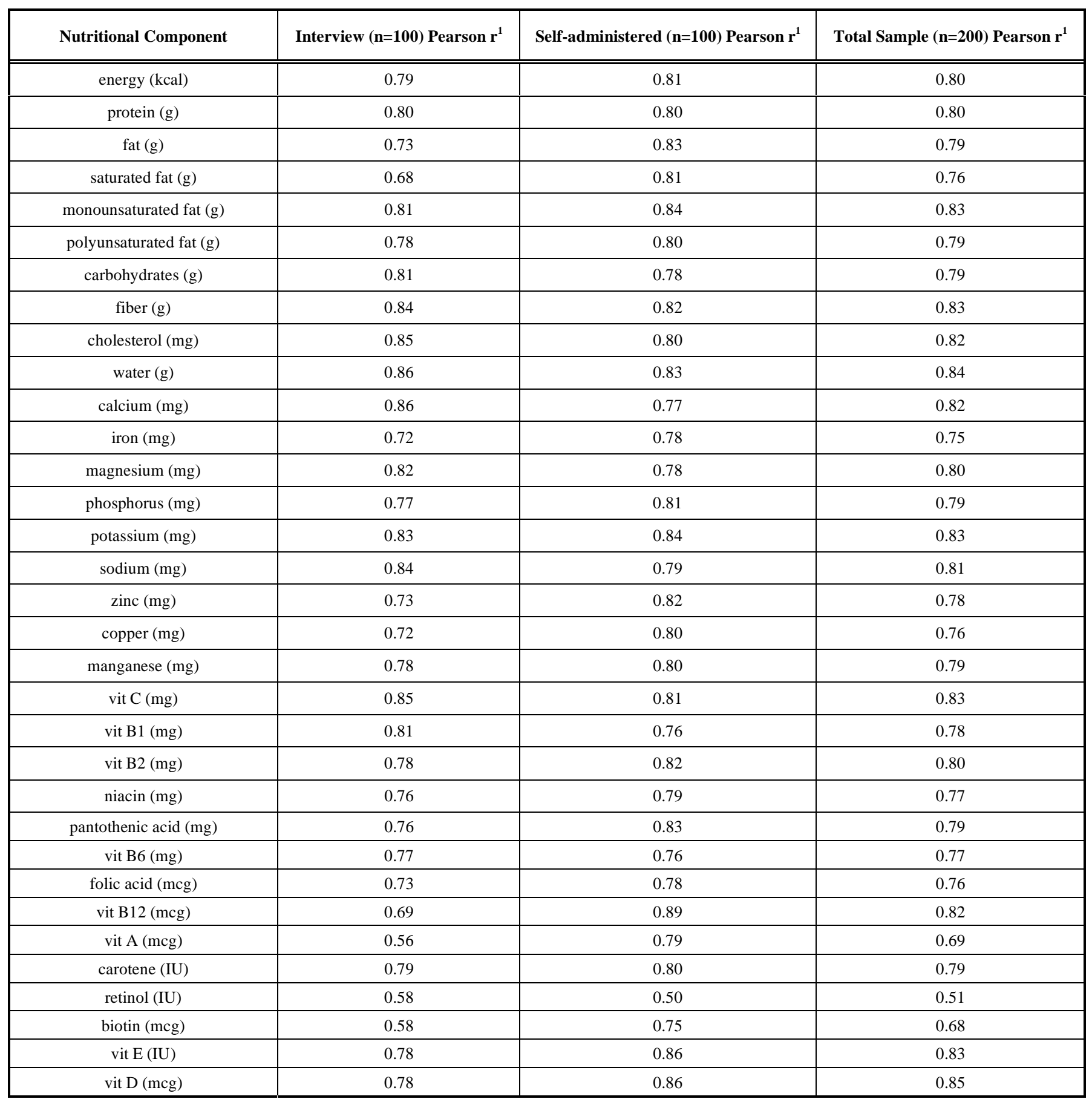

${ }^{1}$ Pearson correlations, all $\mathrm{p}<0.0001$.

items, i.e. the person gave the same answer, \pm 1 category, both times. Percent of calories from proteins, fats and carbohydrates were similar for both self-administered and interviewed groups (Table 1). The majority of correlations between the $1^{\text {st }}$ and $2^{\text {nd }}$ SSFQs for the micronutrients were above 0.75 for the whole sample and within each method of completion (Table 2). Paired t-tests were performed to compare the differences in the actual values obtained from the two SSFQs. Significant differences were found only for cholesterol and water in the total sample, for fiber and water within the interviewed group and for protein, cholesterol, zinc and niacin in the self-administered group (Table 3 ).
The mean difference in total calories, grams of fats, proteins and carbohydrates, between the $1^{\text {st }}$ and $2^{\text {nd }}$ SSFQ, was calculated and compared between the interviewed and selfadministered group. Mean differences were significantly smaller in the interviewed group for the four categories tested (Table 4).

\section{b. Validity}

Two comparisons were made: one of self-administered FFQ compared to interviewer-assisted FFQ, and the second, of FFQ compared to FR. 
Table 3. Comparison of Mean (SD) Consumption Between SFFQ1 and SFFQ2, by Completion Method

\begin{tabular}{|c|c|c|c|c|c|c|c|c|c|}
\hline $\begin{array}{l}\text { Nutritional } \\
\text { Components }\end{array}$ & \multicolumn{3}{|c|}{ Interview $(\mathrm{n}=100)$} & \multicolumn{3}{|c|}{ Self-administered $(n=100)$} & \multicolumn{3}{|c|}{ Total Sample $(\mathrm{n}=\mathbf{2 0 0})$} \\
\hline fiber $(\mathrm{g})$ & $\begin{array}{c}11.7 \\
(6.26)\end{array}$ & $\begin{array}{c}10.9 \\
(5.73)\end{array}$ & 0.04 & $\begin{array}{c}11.9 \\
(6.29)\end{array}$ & $\begin{array}{c}12.1 \\
(7.85)\end{array}$ & 0.78 & $\begin{array}{c}11.8 \\
(6.26)\end{array}$ & $\begin{array}{c}11.5 \\
(6.88)\end{array}$ & 0.26 \\
\hline water $(\mathrm{g})$ & $\begin{array}{c}2339.3 \\
(700.55)\end{array}$ & $\begin{array}{c}2253.3 \\
(684.73)\end{array}$ & 0.03 & $\begin{array}{c}2262.2 \\
(897.37)\end{array}$ & $\begin{array}{c}2158.9 \\
(873.30)\end{array}$ & 0.07 & $\begin{array}{c}2300.7 \\
(803.90)\end{array}$ & $\begin{array}{c}2206.1 \\
(784.16)\end{array}$ & 0.01 \\
\hline zinc (mg) & $\begin{array}{c}6.1 \\
(2.65)\end{array}$ & $\begin{array}{c}6.1 \\
(2.86)\end{array}$ & 0.82 & $\begin{array}{c}6.2 \\
(3.13)\end{array}$ & $\begin{array}{c}5.8 \\
(3.00)\end{array}$ & 0.05 & $\begin{array}{c}6.1 \\
(2.89)\end{array}$ & $\begin{array}{c}6.0 \\
(2.93)\end{array}$ & 0.22 \\
\hline
\end{tabular}

None of the 27 other nutritional components had significant differences in mean consumption.

Table 4. Mean Difference (SD) Between SFFQ1 and SFFQ2 Between Completion Methods

\begin{tabular}{|c|c|c|c|c|c|c|c|}
\hline \multirow{2}{*}{$\begin{array}{c}\text { Nutritional } \\
\text { Components }\end{array}$} & \multicolumn{3}{|c|}{ Interview (n=100) } & \multicolumn{3}{c|}{ Self-administered (n=100) } \\
\cline { 2 - 7 } & SFFQ1 & SFFQ2 & Mean Difference (SD) & SFFQ1 & SFFQ2 & Mean Difference (SD) & Sig. * \\
\hline \hline \multirow{2}{*}{ energy (kcal) } & $\begin{array}{c}1798.5 \\
(612.85)\end{array}$ & $\begin{array}{c}1790.7 \\
(717.25)\end{array}$ & $\begin{array}{c}260.1 \\
(361.89)\end{array}$ & $\begin{array}{c}1858.7 \\
(814.78)\end{array}$ & $\begin{array}{c}1802.45 \\
(884.21)\end{array}$ & $\begin{array}{c}360.0 \\
(364.08)\end{array}$ \\
\hline \multirow{2}{*}{ protein (g) } & $\begin{array}{c}76.1 \\
(26.83)\end{array}$ & $\begin{array}{c}76.9 \\
(29.18)\end{array}$ & $\begin{array}{c}11.5 \\
(12.78)\end{array}$ & $\begin{array}{c}79.1 \\
(34.83)\end{array}$ & $\begin{array}{c}74.7 \\
(34.02)\end{array}$ & $(16.0$ \\
& 64.6 & 64.6 & 11.4 & 64.4 & 63.1 & $\mathbf{0 . 0 2}$ \\
fat (g) & $(24.09)$ & $(28.00)$ & $(15.38)$ & $(33.11)$ & $(35.41)$ & $(13.58)$ \\
\hline \multirow{2}{*}{ carbohydrates (g) } & 229.7 & 227.00 & 36.8 & 241.6 & 235.5 & 0.08 \\
& $(87.43)$ & $(101.04)$ & $(50.11)$ & $(112.92)$ & $(123.30)$ & 52.5 \\
$(58.62)$
\end{tabular}

*comparison of mean differences.

No differences were noted in percent energy from proteins, fats or carbohydrates, between self-administered FFQ, interviewer-assisted FFQ and FR (Table 5). The correlation for percent energy from proteins was the highest and for percent from fats the lowest. Correlation coefficients for total energy, fibers, fats and types of fatty acids (SFA, MUFA, PUFA) as well as proteins and carbohydrates consumed were significant and ranged between 0.54 and 0.29 . Interviewerassisted FFQs were better correlated with FR than selfadministered FFQs for all items other than fats and the different fatty acids (Table $\mathbf{6}$ ).

\section{DISCUSSION AND CONCLUSION}

The Israeli food frequency questionnaire was found in our study to be highly reproducible and valid compared to a dietary record. Repeated measures of reported consumption of food items and their contribution to total caloric intake and to distribution of the source of calories yielded very close results, both for interviewer-assisted and for selfadministered FFQs, with a small advantage to the former. Significant correlations were found between both FFQ methods and the food record method. These correlations were far from being full, though this is reasonable as the two

Table 5. Correlation of Percent Calories from Protein, Fat and Carbohydrates Between SFFQ1 and FR by Completion Method

\begin{tabular}{|c|c|c|c|}
\hline Nutritional Component & Interview (n=100) Pearson $\mathbf{r}^{1}$ & Self-administered $(n=100)$ Pearson $r^{1}$ & Total Sample $(n=200)$ Pearson $\mathbf{r}^{1}$ \\
\hline Protein & $0.54 * * *$ & $0.42 * * *$ & $0.46^{* * *}$ \\
\hline Carbohydrates & $0.35^{* *}$ & $0.33 * *$ & $0.35^{* * *}$ \\
\hline
\end{tabular}

${ }^{1}$ Pearson correlations * $\mathrm{p}<0.01 * * \mathrm{p}<0.001 * * * \mathrm{p}<0.0001$ 
Table 6. Correlation of Percent Calories from Protein, Fat and Carbohydrates Between SFFQ1 and FR by Completion Method

\begin{tabular}{|c|c|c|c|}
\hline Nutritional Component & Interview $(n=100)$ Pearson $r^{1}$ & Self-administered ( $n=100)$ Pearson $r^{1}$ & Total Sample $(n=200)$ Pearson $r^{1}$ \\
\hline energy (kcal) & 0.42 & 0.36 & 0.39 \\
\hline fat $(g)$ & 0.38 & 0.44 & 0.41 \\
\hline saturated fat $(\mathrm{g})$ & 0.30 & 0.45 & 0.39 \\
\hline polyunsaturated fat (g) & 0.34 & 0.41 & 0.38 \\
\hline carbohydrates (g) & 0.45 & 0.29 & 0.37 \\
\hline fiber $(\mathrm{g})$ & 0.54 & 0.36 & 0.45 \\
\hline
\end{tabular}

${ }^{1}$ Pearson correlations, all $\mathrm{p}<0.01$.

methods serve different purposes; one estimating current consumption and the second measuring usual consumption taking into account a long time period and seasonality.

Overall the average correlation was 0.78 , which is comparable, and even superior, to those found in many other studies [4, 12-19] (Table 7). One potential explanation for the higher correlations observed in the present study is that the interval between FFQs was only 3 months in this study design compared to longer intervals in other studies.

Recently, others have criticized FFQs in epidemiologic studies for a variety of reasons, including poor correspondence between energy intake estimated from FFQs compared to energy intake measured from doubly labeled water, and the failure to detect meaningful dietary associations that are clearly appreciated from dietary biomarkers when using FFQs [20]. Indeed, some have argued that the correspondence between FFQs and dietary records may reflect correlated errors. However, the correlations that are observed in the present study are higher than most, and retinol is the only nutritional component measured with a correlation less than 0.75 ( 0.50 for retinol) among the values calculated in this study.

The strength of the current study is that the correlations reported here are not adjusted for total energy intake, which

Table 7. Description of 7 Methodologic Studies of Repeated Food Frequency Questionnaires

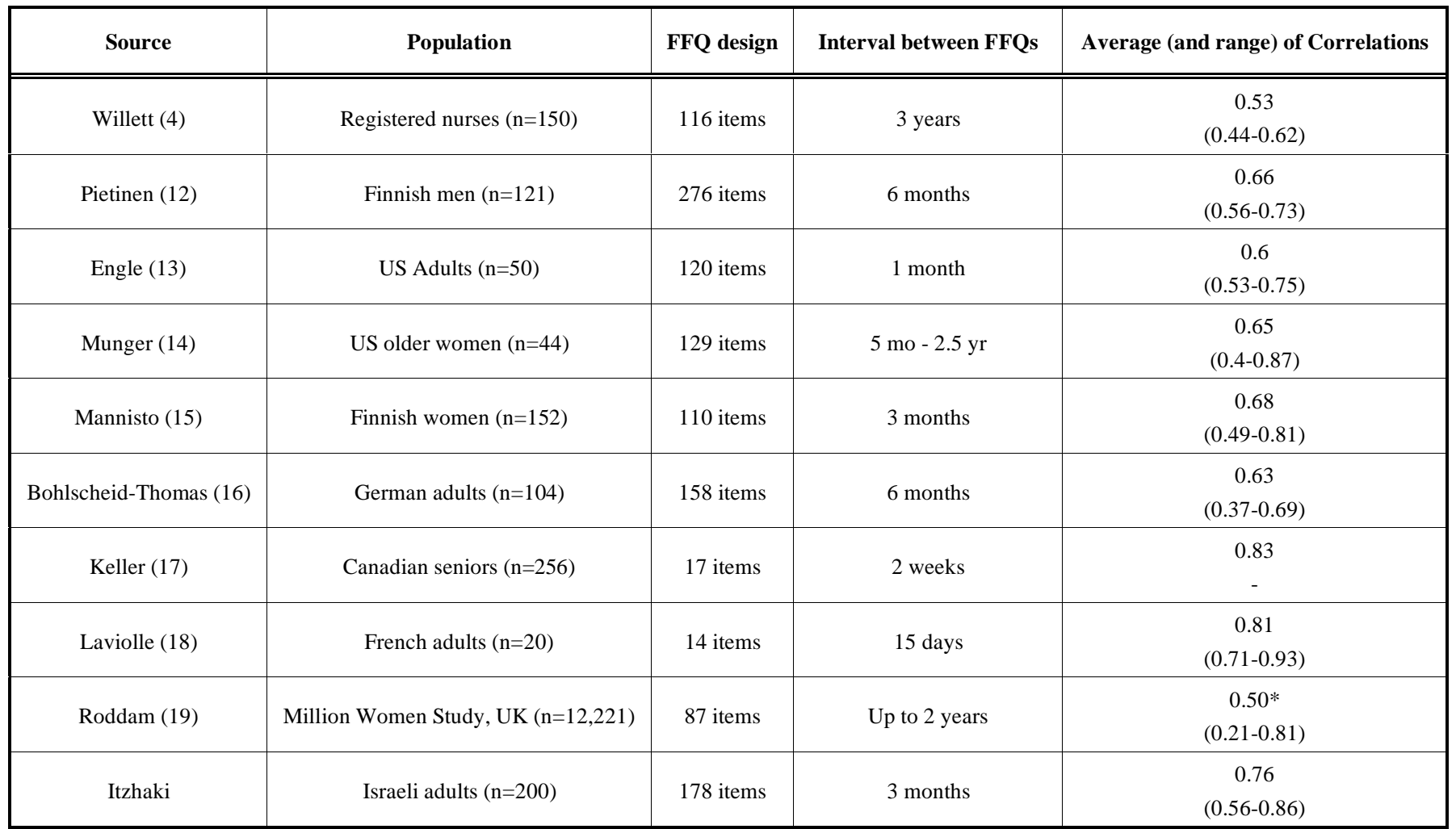

*Kappa. 
tends to inflate correlations. Although the multiplicity of reasons for the high correlations observed in the present study are not entirely clear, we suspect that these results are specific to the Israeli diet and the FFQ adaptation used to measure it. The Israeli diet is rich in vegetables, fruits, grains, and dairy products, the use of which might carry a clearer and repeatable pattern of consumption and which might be easier to quantify than complex dishes.

The evaluated questionnaire, thus, seems suitable for use in epidemiological studies in Israel designed to study the role of overall nutrition and nutritional factors as risk determinants of chronic diseases. Although some have argued that FFQs have outlived their utility in epidemiologic studies, the data in the present study suggest that within specific cultural and dietary contexts, FFQs are still potentially valuable tools in the epidemiologic arsenal.

\section{REFERENCES}

[1] Willett WC. Nutritional epidemiology issues in chronic disease at the turn of the century. Epidemiol Rev 2000; 22(1): 82-6.

[2] Bingham SA, Nelson M. Assessment of food consumption and nutrient intake in: Design Concepts in Nutritional Epidemiology. Oxford 1996; 53-91.

[3] Kohlmeier L. Future of dietary exposure assessment. Am J Clin Nutr 1995; 61(3 Suppl): 702S-709S.

[4] Willett WC, Sampson L, Stampfer MJ, et al. Reproducibility and validity of a semiquantitative food frequency questionnaire. Am J Epidemiol 1985; 122(1): 51-65.

[5] Willett WC, Lenart E. Reproducibility and validity of food frequency questionnaires in: Nutritional Epidemiology and Biostatistics. Oxford University Press 1988; 101-45.

[6] Willett WC, Stampfer MJ, Underwood BA, Speizer FE, Rosner B, Hennekens $\mathrm{CH}$. Validation of a dietary questionnaire with plasma carotenoid and alpha-tocopherol levels. Am J Clin Nutr 1983; 38(4): 631-9.

[7] Hu FB, Rimm E, Smith-Warner SA, et al. Reproducibility and validity of dietary patterns assessed with a food-frequency questionnaire. Am J Clin Nutr 1999; 69(2): 243-9.

[8] Block G. A review of validations of dietary assessment methods. Am J Epidemiol 1982; 115(4): 492-505.
[9] Grootenhuis PA, Westenbrink S, Sie CM, de Neeling JN, Kok FJ, Bouter LM. A semiquantitative food frequency questionnaire for use in epidemiologic research among the elderly: validation by comparison with dietary history. J Clin Epidemiol 1995; 48(7): 859-68.

[10] Block G, Hartman AM. Issues in reproducibility and validity of dietary studies. Am J Clin Nutr 1989; 50(5 Suppl): 1133-8.

[11] Jain M, Howe GR, Rohan T. Dietary assessment in epidemiology: comparison on food frequency and a diet history questionnaire with a 7-day food record. Am J Epidemiol 1996; 143(9): 953-60.

[12] Pietinen P, Hartman AM, Haapa E, et al. Reproducibility and validity of dietary assessment instruments. I. A self-administered food use questionnaire with a portion size picture booklet. Am J Epidemiol 1988; 128(3): 655-66.

[13] Engle A, Lynn LL, Koury K, Boyar AP. Reproducibility and comparability of a computerized, self-administered food frequency questionnaire. Nutr Cancer 1990: 13(4): 281-92.

[14] Munger RG, Folsom AR, Kushi LH, Kaye SA, Sellers TA. Dietary assessment of older Iowa women with a food frequency questionnaire: nutrient intake, reproducibility, and comparison with 24-hour dietary recall interviews. Am J Epidemiol 1992; 136(2): 192-200.

[15] Mannisto S, Virtanen M, Mikkonen T, Pietinen P. Reproducibility and validity of a food frequency questionnaire in a case-control study on breast cancer. J Clin Epidemiol 1996; 49(4): 401-9.

[16] Bohlscheid-Thomas S, Hoting I, Boeing H, Wahrendorf J. Reproducibility and relative validity of food group intake in a food frequency questionnaire developed for the German part of the EPIC project. European Prospective Investigation into Cancer and Nutrition. Int J Epidemiol 1997; 26 (Suppl 1): S59-70.

[17] Keller HH, Goy R, Kane SL. Validity and reliability of SCREEN II (Seniors in the community: risk evaluation for eating and nutrition, Version II). Eur J Clin Nutr 2005; 59(10): 1149-57.

[18] Laviolle B, Froger-Bompas C, Guillo P, et al. Relative validity and reproducibility of a 14-item semi-quantitative food frequency questionnaire for cardiovascular prevention. Eur J Cardiovasc Prev Rehabil 2005; 12(6): 587-95.

[19] Roddam AW, Spencer E, Banks E, et al. Reproducibility of a short semi-quantitative food group questionnaire and its performance in estimating nutrient intake compared with a 7-day diet diary in the Million Women Study. Public Health Nutr 2005; 8(2): 201-13.

[20] Kristal AR, Peters U, Potter JD. Is it time to abandon the food frequency questionnaire? Cancer Epidemiol Biomarkers Prev 2005; 14(12): 2826-8. 